\title{
CONSTRUÇÕES CONDICIONAIS DO PORTUGUÊS BRASILEIRO ESCRITO: UMA PERSPECTIVA DE GRAMÁTICA BASEADA NO USO ${ }^{1}$
}

\author{
CONDITIONAL CONSTRUCTIONS OF THE WRITTEN BRAZILIAN PORTUGUESE: \\ A USAGE-BASED GRAMMATICAL PERSPECTIVE
}

Leyla Ely | Lattes | leyla.ely@outlook.com

Universidade Federal da Fronteira Sul | DS/CAPES |

Universidade Federal do Rio de Janeiro | PROEX/CAPES

Cláudia Andrea Rost Snichelotto | Lattes | claudiarost@uffs.edu.br

Universidade Federal da Fronteira Sul

Resumo: Neste artigo, apresentamos os resultados de uma análise de construções hipotáticas condicionais em dados escritos do português brasileiro contemporâneo, retirados de cartas pessoais de adeus (ELY, 2019). Procedeu-se ao levantamento qualitativo de aspectos linguísticos formais (ordem, conector e forma verbal) e funcionais (modalidade e expressão temporal) das construções condicionais com base na perspectiva da Gramática de Construções Baseada no Uso, que visa ao pareamento simbólico das construções linguísticas. Os resultados apontaram para uma relação entre a construção condicional e a modalidade, sobretudo a epistêmica, vinculado à predominância da ordem sintática canônica, do uso conjuncional prototípico "se" e da temporalidade futura na forma verbal simples em razão do contexto comunicativo da amostra investigada.

Palavras-chave: Construções hipotáticas condicionais. Gramática. Uso linguístico.

Abstract: In this paper we present the result of an analysis of conditional hypothetical constructions in data written in contemporary Brazilian Portuguese gathered from personal "goodbye" letters (ELY, 2019). A qualitative survey of formal (order, connector and verbal form) and functional (modality and temporal expression) linguistic aspects of conditional constructions based on the Usage-Based Construction Grammar perspective, which aims the symbolic matching of language constructions was performed. The results showed a relationship between conditional construction and modality, especially the epistemic one, linked to the predominance of the canonical syntactic order, the use of the prototypical conjunctional "if" and future temporality in the simple verb form due to the communicative context of the investigated sample.

Keywords: Conditional hypothetical constructions. Grammar. Linguistic use.

\footnotetext{
${ }^{1}$ Este artigo é parte revista da dissertação de Ely (2019). Esta pesquisa foi financiada pelo Programa Demanda Social da Capes. Agradecemos gentilmente aos pareceristas anônimos as sugestões. São de nossa inteira responsabilidade eventuais falhas remanescentes.
} 


\section{INTRODUÇÃO}

Neste artigo, analisamos aspectos formais e semântico-pragmáticos que subjazem o uso das construções condicionais em uma amostra sincrônica de dados escritos contemporâneos do português brasileiro (PB) do subgênero cartas pessoais de adeus ${ }^{2}$.

Embora alguns trabalhos (sócio)funcionalistas (NEVES, 1999; BACK, 2008; SOUSA, 2009; COAN, BACK, 2014; OLIVEIRA, 2008, 2009; 2014, para citar alguns) descrevam os usos das construções condicionais para além da estrutura sintática prototípica “Se p, (então) q”, ainda há carência de estudos, principalmente em amostras escritas do $\mathrm{PB}^{3}$, que visam focalizar aspectos formais e semântico-pragmáticos em diferentes construções que acionam a leitura condicional.

Os trechos seguintes ilustram ocorrências de construções condicionais extraídas da amostra:

(1) Se eu tivesse ficado aqui com você Silvia, eu não tinha feito isto. (CEOM/ VMPOSC, r.04F, 1978, cart. 14) ${ }^{4}$;

(2) Só use isso como provas para defender qualquer inocente. (CEOM/ VMPOSC, r.05M, 1979, cart. 20);

(3) Jair porque você faz tudo isso, a vida é bacana amor, vamos esperar que o nosso dia chegará, mas quando será. (CEOM/VMPOSC, r.05F, 1978, cart. 13).

As ocorrências 1) a 3) revelam possibilidades de leitura condicional no PB escrito. Em termos formais, tem-se, na ocorrência 1), presença da conjunção prototípica "se" que encabeça a construção sintática prototípica (prótase > apódase) e as perífrases verbais ("tivesse ficado" e "tinha feito"). Por outro lado, as ocorrências 2) e 3 ) apresentam construções condicionais atípicas em razão do emprego do conector "só", em 2), e "porque", em 3), que encabeçam as orações, além do uso da ordem canônica (2) e inversa (3) e das formas verbais simples e perifrásticas. Em termos semântico-pragmáticos, a relação de sentido condicional, em 1), é veiculada a partir do encadeamento de condição para realização, isto é, da relação causa > consequência entre as proposições (NEVES, 1999; em

\footnotetext{
${ }^{2}$ Nomeamos a amostra analisada de cartas pessoais de adeus em razão do contexto discursivo de produção do gênero, o qual se refere a cartas escritas por pessoas que se suicidaram. Para mais informações a respeito dessa amostra, consulte Ely (2019).

${ }^{3}$ Localizamos até o momento as pesquisas de Hirata-Vale (2005), Oliveira (2008) e Braga e Paiva (2019) que investigaram dados escritos do $\mathrm{PB}$.

4 As siglas CEOM/VMPOSC significam, respectivamente, Centro de Pesquisa do Oeste de Santa Catarina e Variação e Mudança do Português no Oeste de Santa Catarina (VMPOSC). O código r04, por exemplo, identifica o quarto remetente da amostra; a designação de $\mathrm{F} / \mathrm{M}$ corresponde ao sexo/gênero feminino ou masculino; na sequência temos o ano em que a carta foi escrita; e, por fim, enumeramos as cartas da amostra.
} 
2), o conector "só" denota uma condição necessária e suficiente de que "só use isso, se e somente se for para defender qualquer inocente"; e, em 3), embora a relação causal entre as proposições esteja presente, a construção pode ser parafraseada por "se a vida é bacana, por que você faz tudo isso".

Para sustentar a análise do fenômeno, apoiamo-nos nos pressupostos da Gramática Baseada no Uso, conforme Givón (1995; 2002), Croft (2001), Bybee (2010, 2015), Furtado da Cunha (2012), Furtado da Cunha, Bispo e Silva (2013), Traugott e Trousdale (2013), entre outros. A escolha desse quadro teórico decorreu em razão da abordagem ampliar o escopo de análise tanto nos aspectos formais quanto nos funcionais para a explicação do fenômeno, uma vez que entende a gramática enquanto construção (pareamento simbólico entre forma-significado).

Nesse viés, os usos condicionais se configuram como microconstruções codificadas por um conector condicional (CONECT) que encabeça a oração subordinada [(Y) VP (C) ] HIP COND ${ }^{5}$, seguido da oração principal, que pode conter os mesmos elementos linguísticos da subordinada. Assim, o esquema condicional abstrato se constitui da seguinte forma: (CONECT) $[(\mathrm{Y}) \mathrm{VP}(\mathrm{C})]$ HIP COND < > ([(Y) VP (C) ] PRINC) (ELY, 2019). Em outras palavras, a estrutura condicional pode ocorrer tanto na ordem subordinada $>$ principal (prótase > apódose), quanto na ordem inversa principal > subordinada (apódose $>$ prótase), ou ainda ser expressa somente pela oração subordinada ${ }^{6}$.

Em vista de o propósito comunicativo das cartas de adeus ser distinto de outras cartas - por exemplo, da familiar - buscamos responder as seguintes questões: (i) quais propriedades formais e semântico-pragmáticos são motivadas pelas construções condicionais no contexto de despedida?; e (ii) quais os padrões de uso das construções condicionais da amostra?

Formuladas essas questões, com base nos pressupostos teóricos da Gramática Baseada no Uso, buscamos evidências para comprovar as seguintes hipóteses: (i) tanto os aspectos formais, quanto os funcionais atuam no uso e na caracterização das construções condicionais. Entendemos que pode haver pareamento entre forma-significado,

\footnotetext{
${ }^{5}$ Nessa microconstrução, as abreviaturas significam: VP, do inglês phrasal verb, refere-se ao sintagma verbal; Y corresponde à função de sujeito, objeto ou qualquer item que se posicione antes do verbo; e C representa o complemento, que pode ser um objeto direto, por exemplo. Por fim, HIP COND corresponde à abreviatura da oração hipotática condicional. (FERNANDES, 2019).

${ }^{6}$ Rocha Lima (2011, p. 346) denominou esse tipo de construção de condicional subentendida. Neves (2011, p. 855), por sua vez, descreve que essas construções são sintaticamente estruturadas apenas pela prótase, e seu conteúdo constitui uma "moldura de referência condicional", como em: "Se eu tivesse morado com você...” (CEOM/VMPOSC, r.04F, 1978, cart.14).
} 
estabelecidos por um continuum de unidades simbólicas, em que determinada forma serve a propósitos comunicativos específicos. Ou seja, cada microconstrução condicional possui uma interpretação semântica e/ou pragmática como parte de sua descrição (DANCYGIER, 1998); e (ii) algumas combinações do fenômeno condicional são significativamente mais produtivas o que indica a existência de padrões preferenciais conforme Oliveira e Hirata-Vale (2017). Em outras palavras, postulamos que o subesquema CONECT [(Y) (VP) (C)]HIP COND [(Y) (VP) (C)]PRINCIPAL instancia diferentes microconstruções, sendo verificadas empiricamente por construtos como "se", "só se", "desde que" etc. Dentre as possibilidades, acreditamos que a construção considerada prototípica "Se p, q" seja a mais recorrente na amostra, uma vez que essa microconstrução tende a ser empregada mais fortemente pelos usuários da língua (GRYNER,1990; NEVES, 1999).

Este artigo está organizado em cinco seções além desta Introdução. A seguir (2), expomos breve levantamento bibliográfico sobre propriedades formais e funcionais das construções condicionais a partir de uma perspectiva funcionalista; na seção 3 , dissertamos brevemente sobre os subsídios teóricos que respaldam a análise do fenômeno, seguido da metodologia utilizada (4); na sequência (5), por sua vez, apresentamos a análise e a discussão dos padrões de uso das construções da amostra. Por fim, encontram-se as considerações finais.

\section{CONSTRUÇÕES CONDICIONAIS}

As construções condicionais têm sido objeto de estudo de diferentes perspectivas teórico-metodológicas. É o caso, por exemplo, da linha cognitivista (DANCYGIER, 1998; SWEETSER, 1990, FERRARI, 2001, entre outras), da sociolinguista (GRYNER, 1990; 1995; BRANDÃO, 2018 etc.), da sociofuncionalista (COAN, 2003; BACK, 2008; FREITAG, 2011; FREITAG, ARAÚJO, BARRETO, 2013; TAVARES, 2013, entre outros) e da funcionalista (NEVES, 1999; OLIVEIRA, 2008; BITTENCOURT, 2012; COAN; BACK, 2014; BRAGA; PAIVA, 2019, para citar alguns). Tais abordagens descrevem o uso condicional segundo motivações formais e funcionais, cognitivas e extralinguísticas, com base em fatores como idade, sexo/gênero e escolaridade, por exemplo.

Relativo às propriedades formais, as construções condicionais são constituídas por duas proposições interdependentes - prótase e apódose -, que estabelecem uma relação lógica e não-encaixada entre si (NEVES, 1999; HOPPER; TRAUGOTT, 2003). Esse tipo de construção pode ser representado por diferentes construções, conforme a presença ou ausência (elipse conjuncional) de conector, a ordem em que as proposições se organizam, isto é, da prótase $<>$ apódose ou expressa somente pela oração subordina- 
da, ou a forma verbal constitutiva (simples ou perifrástica) do enunciado condicional (OLIVEIRA, 2008, 2014; OLIVEIRA, HIRATA VALE, 2017; BRAGA, PAIVA, 2019).

Apesar de as pesquisas funcionalistas tratarem, mais recentemente, de usos contemporâneos das construções condicionais, as gramáticas tradicionais (BECHARA, 2009; ROCHA LIMA, 2011 [1972], por exemplo) centram sua descrição na estrutura prototípica “Se p, (então) q", como em 4):

(4) Se eu estudar, obterei o prêmio” (BECHARA, 2009, p. 498, grifo nosso),

em que o conector "se" é compreendido como o componente definidor para veiculação da relação condicional. Todavia, autores como Neves (1999), Hirata-vale (2005), Back (2008), Oliveira (2008; 2014) e Oliveira e Hirata-vale (2017) - para citar alguns - têm demonstrado a possibilidade de outros conectivos, como "só se", "desde que", "dado que", "supondo que" etc. poderem introduzir esse tipo de construção ou até mesmo inexistir conector nessas construções para veiculação do significado condicional.

Quanto às propriedades sintáticas, as gramáticas tradicionais dão ênfase de modo predominante à ordem canônica, apesar de admitirem a relação inversa, ou seja, apódose $>$ prótase. A subordinação, sob essa perspectiva, é entendida de forma dicotômica em relação à coordenação, quer dizer, a partir da vinculação de dependência ou independência entre as proposições. Esse entendimento também apresenta limitações, já que, segundo Oliveira (2014), se considerarmos o uso interativo da língua, há diversas estratégias de combinação das orações complexas para além dos descritos na gramática tradicional.

É o que propõem Hopper e Traugott (2003, p. 170 apud ROSÁRIO; BARROS, 2018) a partir da distinção ternária para combinação das orações. Os autores distribuíram as construções complexas em um continuum para a escala de vinculação entre orações subordinadas e principal, que vai da menor dependência e encaixamento entre orações à maior dependência e encaixamento. Nesse continuum (que vai da parataxe à hipotaxe à subordinação, respectivamente), as construções condicionais encontram-se na hipotaxe, isto é, possuem interdependência entre a oração subordinada e a principal (NEVES, 2012), conforme se verifica no Quadro 1 abaixo:

Quadro 1 - Continuum [-dependência][-encaixamento] e [+dependência]

[-encaixamento]

\begin{tabular}{|c|c|c|c|}
\hline & $\begin{array}{c}\text { Parataxe } \\
\text { (independência) }\end{array}$ & $\begin{array}{c}\text { Hipotaxe } \\
\text { (interdependência) }\end{array}$ & $\begin{array}{c}\text { Subordinação } \\
\text { (dependência) }\end{array}$ \\
\hline [Dependência] & - & + & + \\
\hline [Encaixamento] & - & - & + \\
\hline
\end{tabular}

Fonte: Rosário e Barros (2018, p. 368). 
Como vemos, as construções hipotáticas, sobre as quais se inserem as condicionais, assinalam uma relação de interdependência e não-encaixamento entre as cláusulas. Essa vinculação entre as construções pode se assemelhar semanticamente a outras construções hipotáticas adverbiais, como as temporais. Quanto à forma verbal simples ou perifrástica constitutiva do enunciado condicional, as gramáticas tradicionais destacam o uso do verbo na forma simples e, portanto, não dão conta do universo de usos verbais das construções condicionais, que, como vemos, em 5), também ocorrem na forma perifrástica:

(5) Meus filhos faço um pedido, se eu for internado mais uma vez no mesmo hospital de loucos como já fui não quero nada só não me deixem espero que me mandem papeis e lápis ou canetas para eu escrever como eu já sofri e contar o quanto sofri. (CEOM/VMPOSC, r.05M, 1979, cart.21)

Verifica-se, em 5), que a construção condicional é introduzida pelo conector prototípico "se", encontra-se na ordem canônica e as formas verbais são expressas pela perífrase verbal (for internado) na prótase e pela forma simples (quero) na apódose.

No que tange às propriedades funcionais, as construções condicionais estabelecem uma relação de condição para a realização de um fato/evento entre a prótase e a apódose (NEVES, 1999), e podem ser marcadas pela factualidade, eventualidade ou contrafactualidade das proposições. A condicional factual é constituída por um fato verificado (apresentado na prótase), ou seja, assegurado pela veracidade da proposição, seguido por uma consequência necessária ou um elemento conclusivo (na apódose) (NEVES, 1999); na proposição eventual, apresenta-se a casualidade de um fato enunciado na prótase - caso esse evento ocorra, a apódose é tida como certa; e na oração contrafactual há uma inversão de polaridade, isto é, repousam sobre a não realidade do evento (ELY, 2019). Essa relação implica diretamente na expressão temporal das proposições. Conforme Freitag e Araujo (2011), a leitura condicional pode ser marcada por diferentes formas verbais que expressam valores semântico-discursivo nas orações. À exemplo:

(6) Se fosse do meu real prazer mesmo eu faria geografia (GELINS/se ita mb lq 01 apud FREITAG; ARAUJO, 2011, p.201, grifos das autoras).

A construção 6) apresenta uma proposição eventual, em que a informação da apódose (fazer geografia) é tida como certa se a eventualidade de "se fosse do meu real prazer" for satisfeita. Segundo Freitag e Araujo (2011), a condição para que o evento se realize é marcada pelo emprego do futuro do pretérito (faria) na apódose, que expressa uma situação posterior ao momento de fala, ou seja, uma projeção de futuro, mas que se encontra ancorado num momento de referência no passado (pelo emprego da forma de pretérito imperfeito "se fosse"). 
Tendo em vista o que foi sumarizado até aqui, rejeitamos a visão limitada e tradicional de que as construções adverbiais são constituídas apenas por configurações fixas e dicotômicas, pois entendemos que o uso das microconstruções condicionais variam segundo critérios formais e semântico-pragmáticos e, por isso, não pertencem a categorias fechadas. As construções condicionais são estruturas complexas - do tipo hipotática [CONECT $][(\mathrm{Y}) \mathrm{VP}(\mathrm{C})]$ OR HIP -, as quais envolvem um conjunto de padrões rotinizados. Segundo Ferrari (2001), são as características lexicais e estruturais que determinam os construtos específicos derivados do esquema geral, em outras palavras, diferentes traços (formais e de significado) constituem as construções condicionais.

A seguir, discorremos brevemente sobre alguns pressupostos da Gramática Baseada no Uso que julgamos apropriados para a análise do fenômeno.

\section{SUBSÍDIOS TEÓRICOS}

A perspectiva teórica que está ganhando espaço nos estudos funcionalistas brasileiros é o modelo da Gramática de Construções Baseada no Uso. Esta abordagem é uma junção do Funcionalismo norte-americano, postulado por Givón (2002), Bybee (2010, 2015), entre outros, com a perspectiva cognitivista, principalmente a Gramática de Construções, segundo Traugott e Trousdale (2013).

Nesta abordagem, as relações linguísticas são consideradas a partir de rede de construções que são interconectadas por links de nós, que se relacionam por naturezas distintas, sendo a estrutura motivada e regulada por fatores cognitivos e sociocomunicativos (FURTADO DA CUNHA; BISPO; SILVA, 2016). Ou seja, a linguagem é permeada e constituída por atividades cognitivas da mente humana e pelo meio sociocomunicativo em que os indivíduos estão inseridos.

Os mecanismos cognitivos são, portanto, essenciais para a compreensão das motivações linguísticas. É a partir da experiência e do contato com ambiente físico e sociocultural que os processos mentais atuam na e sobre a linguagem. A cognição, em relação com os aspectos linguísticos, pode ser entendida como manifestação contextual, que deriva de pressões interacionais e da experiência sócio-histórica do falante (ROSÁRIO; OLIVEIRA, 2016).

A Gramática de Construções Baseada no Uso compreende a unidade linguística enquanto construção, isto é, a partir da correspondência simbólica entre forma-significado. Esse pareamento - parcialmente arbitrário, é exemplificado por Croft (2001) conforme figura 1 abaixo: 
Figura 1 - Construção linguística.

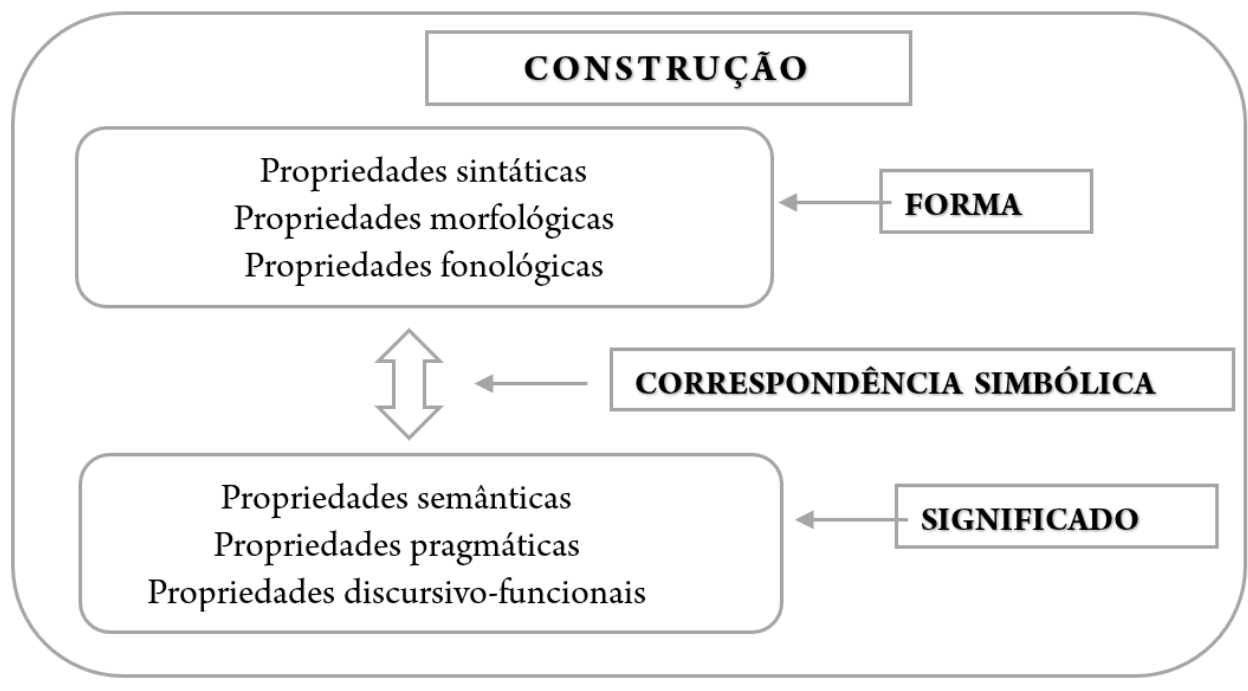

Fonte: Adaptada de Croft (2001, p. 18).

Segundo Croft (2001), é o pareamento simbólico entre forma-significado que constitui a unidade linguística. Em outras palavras, a significação da construção se dá pela relação entre os aspectos fonológicos, morfossintáticos, semânticos, pragmáticos e discursivo-funcionais, os quais são interligados e, por isso, implicam-se mutuamente (ROSÁRIO; OLIVEIRA, 2016). É a partir da relação entre propriedades formais e funcionais que analisamos as construções condicionais de nossa amostra.

Assim, a correspondência simbólica projetada na mente do falante é organizada hierarquicamente, dito de outro modo, as construções linguísticas são mapeadas cognitivamente por construtos, que vão dos mais específicos aos mais abstratos. Representamos essa hierarquia na Figura 2, abaixo:

Figura 2 - Hierarquia construcional.

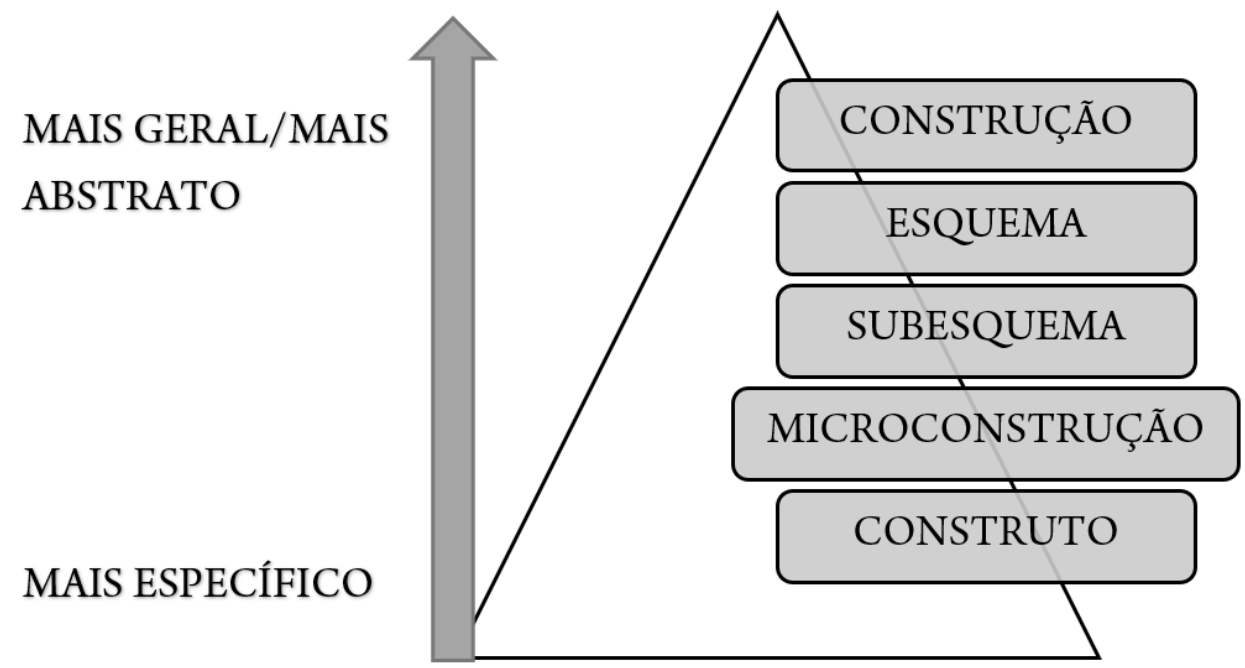

Fonte: Adaptado de Traugott e Trousdale (2013, p. 17). 
A figura acima representa o mapa linguístico mental do falante. Neste caso, as construções são distribuídas em diferentes níveis, em que a construção mais geral se encontra ao topo da hierarquia, e as construções mais específicas se situam nos níveis inferiores do esquema. A base da hierarquia, que inicia com os construtos e chega a um esquema geral, é produzida pelas diferenças de sentido e/ou por propriedades formais de uma construção. Assim, o esquema geral de uma construção é instanciado por subesquemas e, nos níveis mais baixos, por construtos e microconstruções (TRAUGOTT; TROUSDALE, 2013).

Para exemplificar tais pressupostos teóricos, pensemos na construção "(na) hora (em) que”. Na hierarquia dessa construção, conforme Garcia e Sousa $(2018)^{7}$, tem-se a forma "[N $\mathrm{N}$ circunstancial que $]$ CONECT" como sendo a mais esquemática na rede construcional. Nos níveis mais baixos, encontra-se os construtos "na hora em que", "na hora que", "a hora que" e "hora que", os quais são empregados no uso linguístico cotidiano. Verifica-se que da forma mais esquemática para a menos abstrata ocorreram mudanças, tanto na forma quanto na função. Neste caso, o conector reduziu sua forma na hora em que > na hora que > a hora que > hora que e passou a vincular mais função de locução conjuntiva e "menos como um sintagma nominal determinado e modificado por uma oração relativa" (GARCIA; SOUZA, 2018, p. 241). O que promove a instanciação de novas microconstruções é, portanto, a mudança (crescimento ou perda) construcional do próprio esquema (TRAUGOTT; TROUSDALE, 2013).

O modelo teórico baseado no uso propõe algumas categorias de análise para a verificação de tais mudanças, a saber: (i) esquematicidade, (ii) composicionalidade e (iii) produtividade. Isso quer dizer que qualquer esquema hierárquico (Figura 2) se estrutura a partir de um esquema abstrato representado na mente dos falantes. Neste esquema, percebem-se diferentes graus de esquematicidade, pois, quanto maior a abstração, maior será o grau de esquematicidade, e, quanto menor a abstração, menos esquemático e mais concreto o uso será. Outro parâmetro é o da composicionalidade, isto é, a relação de transparência entre forma-função de uma construção; se uma construção não é composicional, haverá incompatibilidade em seu significado ${ }^{8}$ (MARQUES; PINTO, 2016). As constru-

\footnotetext{
${ }^{7}$ Garcia e Souza (2018) analisaram aspectos relativos à mudança construcional e à construcionalização da locução conjuntiva "((n)a) hora em que" de uma amostra oral, extraídas de um banco de dados do português falado no interior paulista. Com base em Traugott (2012) e Traugott e Trousdale (2013), Garcia e Souza (2018) demonstraram que a locução sob análise apresenta graus variados de composicionalidade, produtividade e esquematicidade, que envolvem uma mudança construcional, ou "uma trajetória de construcionalização da forma".

${ }^{8}$ Normalmente, quando uma construção é pouco composicional também será pouco esquemática, mas tende a ser produtiva em frequência de ocorrência (token).
} 
ções mais esquemáticas são também as mais produtivas, no sentido de permitirem uma variação mais ampla de usos linguísticos e de entradas lexicais a preencherem os slots das construções. A produtividade também pode estar ligada ao uso frequente de type (tipo), ou seja, "ao número de expressões de um padrão em particular" (MARQUES; PINTO, 2016, p. 130), ou à frequência token, neste caso, ao número de vezes que determinado tipo ocorre na língua.

No caso das construções “(n(a) hora (em) que”, conforme Garcia e Souza (2018), a construção mais esquemática é a forma "[Ncircunstancial que $]$ CONECT", porque dela deriva outras formas mais concretas, como os conectores "na hora em que", "na hora que", "a hora que" e "hora que", por exemplo. A construção "na hora em que" demonstrou-se a estrutura com maior grau de composicionalidade da amostra, diferentemente do conectivo "hora que" que foi a construção menos composicional, pelo fato de possuir seus itens mais integrados uns aos outros, fazendo com que todas as partes sejam necessárias para a compreensão de seu sentido. E, por fim, de todos os tipos de conectores apresentados na pesquisa (types), "a hora que" foi o token mais frequente, quer dizer, teve maior empregabilidade, sendo esta a preferência dos falantes no uso cotidiano.

A seguir, discorremos sobre os domínios funcionais de tempo e de modalidade, intrínsecos às construções condicionais (ELY, 2019).

\subsection{Domínios funcionais de tempo e de modalidade}

As categorias de tempo e de modalidade se interligam, sendo depreendidas, metodologicamente, com base nos contextos de realização. $\mathrm{O}$ tempo pode referenciar pontos sequenciais cronologicamente marcados (tense) ou se ligar à experiência e à descrição sobre o mundo (time). A modalidade, por outro lado, "coloca em perspectiva a atitude do falante para com o conteúdo proposicional (se certo, possível, provável, improvável, incerto)" (COAN; BACK, 2014, p. 260).

Givón (2002) propõe que a modalidade seja pragmática e comunicativamente motivada, pois recobre a perspectiva e a intencionalidade do falante. A intencionalidade refere-se à informação subjetiva contida na proposição enunciada, uma vez que os valores expressos são transmitidos pela interação entre os interlocutores (BITTENCOURT, 2012). Esses valores, comumente, são inseridos em duas categorias modais: a epistêmica e a deôntica. A primeira refere-se à avaliação que o falante faz da situação enunciada a partir de seus conhecimentos de mundo. Essas crenças envolvem valores como verdade, probabilidade ou (in)certeza. Já a segunda (deôntica) diz respeito à vontade do locutor, 
isto é, o que o falante quer que se faça e como quer que seja feito. Consequentemente, é marcada por valores como: desejo, obrigação, proibição, intenção, manipulação ou preferência do falante (GIVÓN, 1995; 2002).

A marcação da modalidade pode ser feita por meio de diferentes dispositivos linguísticos no ato comunicativo, como a escolha de determinada palavra, de um advérbio específico, ou, até mesmo, pelos tempos e modos verbais. Pensando nisso, Givón (2002) cita o exemplo dos verbos modais "dever" e "precisar", os quais podem expressar o valor de obrigação/imposição, bem como o de probabilidade (Ele pode/deve vir hoje ${ }^{9}$ ). Nestes casos, o significado é dependente do contexto em que é produzido.

Quanto à marcação temporal, nas línguas naturais, o tempo pode ser expresso a partir de um ponto referencial. De acordo com Corôa (2005), Reichenbach propôs três pontos temporais referenciais para marcar os tempos do verbo, são eles: momento da fala $(\mathrm{MF})$, momento do evento (ME) e o ponto de referência (MR). O MF relaciona-se ao ato da comunicação e à pessoa do discurso, uma vez que condiz ao momento em que o enunciado é pronunciado. $\mathrm{O} \mathrm{ME}$ é o tempo da realização do predicado, pois diz respeito ao tempo em que se dá o evento descrito. E, por fim, o MR, que remete aos acontecimentos naturais ou históricos, os quais são compreendidos como o "tempo dos relógios e calendários" (CORÔA, 2005, p.9). Segundo Freitag et al. (2006), o tempo verbal expressa, portanto, uma sequência de eventos.

Dessa forma, o PB apresenta a referência temporal de presente (que ocorre simultaneamente à enunciação), passado (o qual possui relação de anterioridade ao evento da enunciação) e futuro (posterior ao momento enunciativo). Lembrando que a noção de tempo envolve a relação entre o momento em que o evento ocorre e algum outro tempo de referência, sendo associado ao tempo de fala (GIVÓN, 2002). Isso não significa que essa marcação ocorre, necessariamente, pelo tempo gramatical (tempo-modo verbal).

No que se refere às construções condicionais do PB, a modalidade está interligada à expressão temporal das proposições ou ao contexto discursivo (BITTENCOURT, 2014), por exemplo:

(7) Se não for para viver com vocês não quero mais nem me pintando de ouro [...] (CEOM/VMPOSC, r.05M, 1979, cart.16),

em que está se falando de um possível acontecimento que, caso se realize, será em um futuro próximo, uma vez que o remetente projeta a possibilidade de sair da clínica onde se encontra e, então, viver com o destinatário da carta. Ou seja, estamos lidando

\footnotetext{
9 Exemplo retirado de Givón (2002, p.173).
} 
com a modalidade epistêmica, vinculada à expressão de possibilidade e à temporalidade futura.

Pensando nisso, faz-se necessário compreender de que maneira tais categorias funcionais dialogam com as formais - conector, ordem e forma verbal. A seguir, detalhamos a metodologia empregada para a produção desta análise.

\section{METODOLOGIA}

As construções condicionais analisadas neste artigo foram coletadas do corpus do projeto Variação e Mudança do Português no Oeste de Santa Catarina (VMPOSC) ${ }^{10}$. O subgênero cartas pessoais de adeus nos chamou a atenção porque foi redigido por pessoas que se suicidaram (ou trocadas antes do ato em si) em ambiente privado e também devido a certa recorrência de estruturas condicionais prototípicas e atípicas no material. Nossa amostra é composta por 24 (vinte e quatro) cartas pessoais escritas em português contemporâneo brasileiro do período de 1970 a 1990. As cartas constituem material de arquivo público anexo a inquéritos policiais cedidos ao Centro de Pesquisa do Oeste de Santa Catarina (CEOM). Nesse universo, identificamos 28 ocorrências de construções condicionais nas cartas. É preciso ponderar, evidentemente, que a amostra é quantitativamente restrita, mas cremos que já seja suficiente para sinalizar qualitativamente alguns indícios dos tipos de relações e padrões de uso instaurados pelas construções condicionais nesse contexto de produção.

Quanto ao tratamento dos dados para a transcrição, adotamos uma escrita conservadora, o que quer dizer que mantivemos a redação das cartas no que tange aos aspectos gramaticais e ortográficos. Também atribuímos codinomes aos participantes da interação, a fim de manter o anonimato dos envolvidos, embora o material analisado seja de domínio público no $\mathrm{CEOM}^{11}$.

Cabe destacar também que optamos por ampliar o escopo de análise para além do que tem sido feito pelas gramáticas tradicionais, ou seja, procedemos à análise não só das construções condicionais prototípicas, mas também das estruturas atípicas (em que pode haver apenas oração hipotática construcional sem apódose; uso de outro conector interfrásico, como "só", "só se" e "desde que”, entre outros; ou elipse conjuncional; ou formas verbais perifrásticas) da amostra.

${ }^{10}$ O VMPOSC visa a constituir um banco de dados representativo de amostras de fala e de escrita do português de Chapecó (SC) e região (ROST SNICHELOTTO, 2012). Atualmente, sob o escopo do VMPOSC, é desenvolvido o subprojeto "A escrita da região oeste de Santa Catarina: variação e mudança linguística”, que recebe o apoio financeiro da FAPESC e da UFFS (Chamada Pública FAPESC No 03/2018).

${ }^{11}$ A verificação pode ser encontrada em: http://conarq.gov.br/consulta-a-entidades/item/centro-dememoria-do-oeste-de-santa-catarina.html. 
A seguir, caracterizamos e exemplificamos qualitativamente os aspectos formais e funcionais das construções condicionais controladas, além de discutirmos três parâmetros que vêm sendo apontados como relevantes quantitativamente para a análise construcional: grau de esquematicidade, produtividade (verificação da frequência de ocorrência e de entrada) e grau de composicionalidade a fim de identificar os padrões de uso das condicionais em nossa amostra.

\section{APRESENTAÇÃO E ANÁLISE DAS CONSTRUÇÕES CONDICIONAIS DA AMOSTRA}

Caracterizamos e ilustramos, a seguir, os elementos formais controlados nas construções condicionais da amostra: (i) ordem (prótase > apódose ou apódose > prótase ou sem apódose); (ii) presença (se ou X que ou só $\mathrm{X}$ ) ou ausência de conector (elipse conjuncional); e (iii) forma verbal (simples ou perifrástica).

Ordem:

(8) [Canônica]: Se um dia souber que te esqueci, reze por mim porque, nesse dia morri. (CEOM/VMPOSC r.03F, 1978. cart.12/13);

(9) [Inversa]: Desculpe se eu me apaixonei pela pessoa errada, igualmente me mande sua resposta, pois estou esperando-a com esperanças de que você goste de mim. (CEOM/VMPOSC, r.07M, 1986, cart.23);

(10) [Sem apódose]: Se eu tivesse morado com você.... (CEOM/VMPOSC, r.04F, 1978, cart.14).

Na ocorrência 8), a construção se realiza na ordem canônica, isto é, a prótase seguida da apódose, em que a estrutura apresenta uma relação de iconicidade. A oração introduzida por "se" expõe a condição de uma possível causa, neste caso, o esquecimento, seguido da consequência/resultado desta condição, ou seja, a possibilidade de "morte" (termo empregado metaforicamente) do remetente. Por outro lado, em 9), a construção ocorre na ordem inversa, ou melhor, a apódose seguida da prótase, marcada por um pedido subjetivo e pelo modo imperativo, o que é frequente em condicionais mais discursiva e menos temporais (BITTENCOURT, 2014). Em 10), a construção condicional não apresenta apódose, neste caso, o conteúdo da proposição principal deve ser retomado pelo contexto. Este tipo de construção denomina-se de condicional subentendida (ROCHA LIMA, 2011, p. 346), do mesmo modo que em "se ele deixasse..." ou "quisera eu ter morado com você....”

Seguindo a análise dos dados, apresentamos, abaixo, construções iniciadas por diferentes conectores e uma ocorrência de elipse conjuncional. 
Presença ou ausência de conjunção:

(11) [Prototípica]: Se for nosso destino um dia nos encontramos e seremos felizes, (CEOM/VMPOSC, r.03F, 1978, cart.12);

(12) [Só $\mathbf{X}$ ]: Só use isso como provas para defender qualquer inocente. (CEOM/ VMPOSC, r.05M, 1979, cart.20);

(13) [XQUE]: [...] agora não tenho mais razões para viver, estou louca desde que soube de meus 30 dias, para retirar-me da firma. (CEOM/VMPOSC, r.01F, 1976, cart.05);

(14) [Elipse conjuncional]: Jair por que você faz tudo isso, a vida é bacana amor, vamos esperar que o nosso dia chegará, mas quando será (CEOM/VMPOSC r.05F, 1978, cart.13).

Na ocorrência 11), verifica-se o uso da conjunção prototípica "se", que introduz a construção condicional, cujo uso é mais recorrente na língua PB, o que também se confirmou em nossa amostra. Em 12), o uso da conjunção "só" marca a bicondicionalidade da proposição, isto é, o remetente afirma que as provas podem ser utilizadas só e somente se forem para defender inocentes, caso contrário há o impedimento da carta servir como testemunho da causa do ato de suicídio. Em 13), a representação de Xque é ocupada pela junção da preposição "desde" com o complemento "que”, que forma um novo chunk, neste caso, o conector condicional "desde que". Nesta sentença, tem-se uma polissemia semântica, pois a construção hipotática pode se referir tanto à construção temporal quanto à condicional. A leitura condicional é feita considerando o contexto linguístico, podendo ser parafraseado por: Se não tenho mais razões para viver, é porque soube de meus 30 dias. Diferentemente das construções até então discutidas, a ocorrência 14) não possui conector condicional, trata-se de um caso de elipse. O valor condicional é verificado a partir da relação causal, de causa > consequência, e pela substituição por outras conjunções, como "já que”, “uma vez que” - pautados nas explicações de Neves (1999) sobre a troca de conectores condicionais. A paráfrase que fizemos, portanto, foi "Se a vida é bacana amor, porque você faz tudo isso".

Forma verbal:

(15) [Simples]: [...] se desse pelo menos eu dormir lá naquela cozinha de vocês CEOM/VMPOSC, r.05M, 1979, cart.16);

(16) [Perifrástica]: Meus filhos faço um pedido, se eu for internado mais uma vez no mesmo hospital de loucos como já fui não quero nada só não me deixem espero que me mandem papeis e lápis ou canetas para eu escrever como eu já sofri e contar o quanto sofri. (CEOM/VMPOSC, r.05M, 1979, cart.21). 
O último critério formal analisado refere-se à forma verbal das proposições, isto é, se o verbo se encontra na forma simples ou na perifrástica. Estabelecemos este critério, porque pretendemos verificar como ocorre esse uso nas relações linguísticas cotidianas, dado que as gramáticas tradicionais descrevem, normalmente, apenas o uso na forma simples. Assim, em 15), tem-se a forma simples, que indica um fato possível de ser realizado, implicando, neste caso, uma proposição eventual futura. Em 16), emprega-se a forma perifrástica. Nesta sentença, vincula-se, também, uma possibilidade futura, por conta do modo subjuntivo, mas que está mais distante do momento da fala (MF).

$\mathrm{Na}$ sequência, caracterizamos e ilustramos os elementos funcionais controlados nas construções condicionais da amostra: (iv) modalidade (deôntica ou epistêmica); e (v) temporalidade (referência de presente, de passado e de futuro) das construções.

Modalidade:

(17) [Epistêmica]: [...] estou no quinto andar e sair daqui só se for de paraquedas porque a porta do elevador está sempre chaviada. (CEOM/VMPOSC, r.05M, 1979, cart.16);

(18) [Deôntica]: Tu diz para o Marcos que se ele não vendeu aquele toca fita, para não botar fora, que eu compro ele, porque ele me ofereceu quando eu estive ai e pago na boca da guaica. (CEOM/VMPOSC, r.05M, 1979, cart.17);

Em 17), tem-se a modalidade epistêmica vinculada à expressão de possibilidade. Neste caso, o remetente avalia a situação vivenciada e, a partir disso, enuncia a proposição com base em suas crenças de mundo. Por outro lado, em 18), a modalidade deôntica está ligada à intenção e à preferência do falante, visto que a intenção por parte do remetente na compra do "toca fita", e, por isso, há um desejo e um pedido destinado ao leitor da carta. Esse pedido é realizado por meio do verbo na forma imperativa.

Temporalidade:

(19) [Presente]: Alex ajude (no) o que pode a Joana pois apesar de tudo eu gosto dela. (CEOM/VMPOSC, r.07M, 1986, cart.24);

(20) [Passada]: Se eu tivesse morado com você... (CEOM/VMPOSC, r.04F, 1978, cart.14);

(21) [Futura]: Olhe Beatriz fassa o que você quizer porque se você quizer leva para frente pode levar. (CEOM/VMPOSC, r.04F, 1978, cart.15). 
Na ocorrência 19), vê-se uma construção não prototípica, em que ocorre elipse conjuncional. Esta construção expressa o verbo no modo imperativo e no momento presente, pois há um pedido ao destinatário, de que, "se puder, cuide da Joana". Já em 20), tem-se um momento passado que não ocorreu, em virtude de o remetente hipotetizar sobre como seria se tivesse morado com a destinatária - talvez os eventos ocorressem de outra forma. Essa condição não realizada também envolve uma expressão de desejo. E, em 21), verifica-se a expressão futura, pois a remetente apresenta uma condição sobre um ato que a destinatária pode vir a fazer.

Quanto à expressão temporal de passado, obtivemos apenas um dado (exemplo 20). Acreditamos que esta única ocorrência se deva ao contexto das cartas de adeus, que criam diferentes espaços mentais com base na decisão já tomada, mas que ainda não se concretizou, isto é, a de suicidar-se. Sendo assim, tem-se, predominantemente, a expressão futura. Lembramos que a análise sobre a expressão temporal nem sempre condiz ao tempo-modo do verbo, nestes casos, o contexto discursivo é determinante.

Com base no que foi exemplificado acima, foi possível identificar 28 ocorrências de construções condicionais na amostra de 24 cartas investigadas, que sistematizamos na Tabela (1) a seguir:

Tabela 1 - Construções condicionais nas cartas pessoais de adeus.

\begin{tabular}{|c|c|c|c|}
\hline \multicolumn{4}{|c|}{ CONSTRUÇÕES CONDICIONAIS NAS CARTAS DE ADEUS } \\
\hline \multicolumn{2}{|c|}{ Aspectos Formais } & \multicolumn{2}{|c|}{ Aspectos Funcionais } \\
\hline \multirow{3}{*}{ Ordem } & Canônica - 20 (71\%) & \multirow{3}{*}{ Temporalidade } & Futura - $19(68 \%)$ \\
\hline & Inversa $-06(21 \%)$ & & Presente $-08(28 \%)$ \\
\hline & Sem apódose $-02(8 \%)$ & & Passada - $01(4 \%)$ \\
\hline \multirow{4}{*}{ Conjunção } & se $-21(75 \%)$ & \multirow{4}{*}{ Modalidade } & $\begin{array}{c}\text { Epistêmica - } 19 \\
(68 \%)\end{array}$ \\
\hline & Elipse - $03(11 \%)$ & & Deôntica - $09(32 \%)$ \\
\hline & Só X - 03 (11\%) & & \\
\hline & Xque - $01(4 \%)$ & & \\
\hline \multirow{2}{*}{ Forma verbal } & Simples $-21(75 \%)$ & & \\
\hline & Perifrástica - 07 (25\%) & & \\
\hline
\end{tabular}

Fonte: Adaptada de Ely (2019, p. 95-109).

No que tange aos aspectos formais, a maior recorrência de construções condicionais se dá na ordem canônica (71\%), com conjunção "se" (75\%) e forma verbal simples (75\%) devido ao uso icônico, em que a ordem direta e a conjunção "se" são as formas 
prototípicas e de relação lógica das proposições adverbiais condicionais. O uso majoritário da forma verbal simples pode decorrer por conta de serem dados escritos, nos quais a pressão normativa parece estar mais presente, mas também porque refere-se a contextos de menos complexidade cognitiva, ou seja, que demandam mais tensão e envolvimento emocional e menos tempo de processamento - principalmente por serem cartas pessoais. Esses resultados parecem apontar também para uma interferência estilística, pois, apesar de ser um texto escrito, apresenta certo grau de informalidade que se observa pela forma como foram redigidos os aspectos gramaticais e ortográficos das cartas.

Conformeos dados obtidos, o esquema condicional representadopor ([CONECT $]$ ) $[(\mathrm{Y})(\mathrm{NEG}) \mathrm{VP}(\mathrm{C})]_{\mathrm{COND}}\left([(\mathrm{Y})(\mathrm{NEG}) \mathrm{VP}(\mathrm{C})]_{\mathrm{PRINC}}\right)$ é o esquema mais geral e mais abstrato, localizando-se no topo da hierarquia construcional. É também o mais produtivo, porque há ampla variabilidade de preenchimento (novas entradas linguísticas) nos slots das construções. Por exemplo, o slot de "Conect" permite que os falantes empregam diferentes conectores para acionar a leitura condicional, em que tivemos os conectores "se", "desde que", "só" e "só se" ocupando seu lugar. A frequência de tipos (type) não foi tão produtiva - contrapondo nossa amostra aos exemplos apresentados em Neves (1999) e Oliveira $(2008,2014)$, por exemplo. Já as construções (tokens) mais frequentes foram as que ocupam o lugar de "SECONECT" na rede condicional, sendo esses os construtos mais regulares da amostra.

No que diz respeito aos fatores funcionais, majoritariamente o uso mais produtivo é o da expressão temporal futura (68\%) e da modalidade epistêmica (68\%). Acreditamos que isso ocorra por conta de o contexto comunicativo envolver a crença do remetente sobre os fatos enunciados, os quais ocorrerão em um futuro próximo. Ainda sobre a função dos condicionais nas cartas de adeus, pontuamos que o sentido discursivo-pragmático vinculado pelas construções se diferencia de outros contextos porque estão em um propósito comunicativo que cria outros espaços mentais, embora siga-se estruturas já apresentadas em outros trabalhos - o que ratifica nossa hipótese inicial. Sobre os espaços mentais, percebe-se que o remetente, por vezes, projeta a ação como algo já realizado, quando, na verdade, refere-se a uma realização futura. Isso ocorre porque, no imaginário de quem escreve, o ato já está consumado (neste caso, o ato de tirar sua própria vida), e está prestes a realizar a ação, tomando o evento como certo e concluído.

A partir desses resultados, que se baseiam na análise construcional de língua, as construções condicionais são estruturadas com base na relação simbólica entre forma e significado. Verificamos, a partir dos dados analisados, que os aspectos formais se li- 
gam diretamente aos funcionais, pois os resultados mostraram uma forte relação entre a construção hipotática condicional e a modalidade, sobretudo a epistêmica, vinculado à predominância da ordem canônica, do uso conjuncional prototípico "se" e da temporalidade futura na forma verbal simples em razão do contexto comunicativo da amostra investigada.

Assim, as construções condicionais presentes nas cartas pessoais de adeus possuem relação estreita com a modalidade e a marcação temporal, inferindo expressões de possibilidade e incerteza, os quais remetem ao futuro próximo. Essas estruturas são implicadas pelo contexto das cartas, que abrangem a criação de um espaço mental predisposto ao ato de tirar a própria vida, ou melhor, o remetente escreve como se o suicídio fosse algo consumado e, por isso, projeta ações futuras após sua morte voluntária.

\section{CONSIDERAÇÕES FINAIS}

Neste artigo, apresentamos o resultado de uma análise de construções hipotáticas condicionais em dados escritos do português brasileiro contemporâneo, à luz da Gramática de Construções Baseada no Uso. Pretendeu-se contribuir com a descrição do fenômeno na língua portuguesa brasileira, no sentido de fornecer explicações sobre a correspondência simbólica de construções hipotáticas condicionais, em que diferentes espaços mentais são acionados para o uso de determinada estrutura condicional.

Ao longo deste texto buscamos responder a duas questões. A primeira questão diz respeito às motivações formais e semântico-pragmáticos das construções condicionais no contexto de despedida. Os resultados qualitativos apontaram que tanto os aspectos formais, quanto os funcionais atuam no uso e na caracterização das construções condicionais, pois se evidenciou forte relação entre a construção hipotática condicional e a modalidade, sobretudo a epistêmica, vinculado à predominância da ordem canônica, do uso conjuncional prototípico "se" e da temporalidade futura na forma verbal simples em razão do contexto comunicativo da amostra investigada. Entendemos assim que há pareamento entre forma-significado, estabelecidos por um continuum de unidades simbólicas, em que determinada forma serve a propósitos comunicativos específicos. Ou seja, cada microconstrução condicional possui uma interpretação semântica e/ou pragmática como parte de sua descrição (DANCYGIER, 1998).

A segunda questão levantada refere-se aos padrões de uso das construções condicionais da amostra. Postulamos que algumas combinações do fenômeno condicional 
seriam significativamente mais produtivas, o que indica a existência de padrões preferenciais de uso, conforme Oliveira e Hirata-Vale (2017). Em outras palavras, postulamos que o subesquema CONECT [(Y) (VP) (C)]HIP COND [(Y) (VP) (C)]PRINCIPAL instancia diferentes microconstruções, sendo verificadas empiricamente por construtos como "se", "só se", "desde que” etc. Dentre as possibilidades, acreditávamos que a construção considerada prototípica “Se p, q" fosse a mais recorrente na amostra, uma vez que essa microconstrução tende a ser empregada mais fortemente pelos usuários da língua (NEVES, 1999; GRYNER,1990). Os resultados ratificaram nossa hipótese, tendo em vista que o uso mais produtivo da amostra foi SE $[(\mathrm{Y})$ (NEG) VP (C)]COND > [(Y) (NEG) VP (C)]PRINC, em que atribuímos a alta recorrência à motivação icônica das proposições. Os construtos que geram o esquema abstrato são "se", "só", "só se”, "desde que" e elipse conjuncional. Estes construtos diferem em alguns aspectos composicionais, como a ordem das proposições, o conector interfrásico e a forma verbal, mas compartilham da mesma relação semântica, neste caso, a condição de um fato enunciado, seja para reforçar o ponto de vista do interlocutor, seja para expressar as atitudes de probabilidade, incerteza ou desejo sobre uma situação passada, presente ou futura.

A situação de produção se demonstrou elemento fundamental, pois apontou para a relação semântica-pragmática das construções condicionais encontradas e o contexto discursivo das cartas pessoais de adeus, que se diferem de outros usos condicionais em situações cotidianas, por exemplo. O momento de produção das cartas revela que as construções condicionais são usadas para convencer o interlocutor sobre a decisão tomada e, também, como forma de representar algo planejado que sucederá em acontecimentos futuros, isto é, após a morte voluntária. Estas construções, embora sigam estruturas sintáticas conhecidas/já estudadas, vinculam função discursiva-pragmática própria ao contexto discursivo das cartas.

Destaca-se a relevância da discussão proposta se dá pela ampliação na descrição do fenômeno, uma vez que não analisamos apenas as propriedades formais dos enunciados condicionais, e tampouco somente as construções introduzidas por "se", como é comum em gramáticas tradicionais, por exemplo, mas investigamos os diferentes usos condicionais do PB escrito, centrando-nos no pareamento simbólico entre forma-significado inerente às construções. Vale salientar, por fim, o ineditismo de se considerar como objeto de análise construções condicionais em cartas escritas por suicidas, embora estejamos cientes da limitação quantitativa de dados coletados para nossa análise. 


\section{Referências}

BACK, A. C. D. P.. A multifuncionalidade da fora verbal -sse no domínio funcional TempoAspecto-Modalidade: uma abordagem sincrônica. Tese (Doutorado em Linguística) Programa de Pós-Graduação em Linguística, Universidade Federal de Santa Catarina, Centro de Comunicação e Expressão. Florianópolis, SC. 2008.

BECHARA, E.. Moderna gramática portuguesa. 37. ed. Rio de Janeiro: Nova Fronteira, 2009.

BITTENCOURT, D. L. R. A.. A construção condicional hipotética e a modalidade: uma inter-relação lógica. Cadernos do IL, Porto Alegre, no 44, junho de 2012. p. 75-96. Disponível em: <https://seer.ufrgs.br/cadernosdoil/article/view/28128> Acesso em: 15 nov. 2019.

BITTENCOURT, D. L. R. A.. O domínio funcional do futuro do subjuntivo: entre temporalidade e modalidade. Tese (Doutorado em Linguística) - Programa de pósgraduação em Linguística, Universidade Federal de Santa Catarina, Florianópolis, 2014. Disponível em: https://repositorio.ufsc.br/xmlui/handle/123456789/130946. Acesso em: 08 out. 2019.

BRAGA, Maria Luiza; PAIVA, Maria da Conceição. Orações de tempo, causa e condição ao longo dos séculos XVIII a XXI. In: CASTILHO, Ataliba T. de.S (Coord.). História do Português Brasileiro. São Paulo: Contexto, 2019. (História do português brasileiro; 5). p. 170-221.

BRANDÃO, S. M.. Alternância verbal em construções condicionais. 2018, p. 146. Dissertação (Mestrado em Linguística) - Programa de Pós-Graduação em Linguística e Língua Portuguesa. Universidade Estadual Paulista "Júlio de Mesquita Filho", São Paulo 122 (SP), 2018. Disponível em: <https://repositorio.unesp.br/handle/11449/153165> Acesso em: 03 nov. 2019.

BYBEE, J.. Language, usage and cognition. Cambridge University Press, New York, 2010.

BYBEE, J.. Language Change. Cambridge: Cambridge University Press, 2015.

COAN, M.. As categorias tempo, aspecto, modalidade e referência na significação dos pretéritos mais-que-perfeito e perfeito: correlações entre função(ões)-forma(s) em tempo real e aparente. Tese (Doutorado em Linguística) - Programa de Pós-Graduação em Linguística, Universidade Federal de Santa Catarina, Centro de Comunicação e Expressão. Florianópolis, SC. 2003.

COAN, M.; BACK, A. C. P.. Identidades aspecto-temporais do pretérito imperfeito do subjuntivo. Cadernos de estudos lingüísticos. Campinas, 2014, p. 259-272. Disponível em: https://periodicos.sbu.unicamp.br/ojs/index.php/cel/article/view/8641478/8995. acesso em: 04 abril 2020.

CORÔA, M. L. M. S.. O tempo nos verbos do português: uma introdução à sua interpretação semântica. São Paulo: Parábola Editorial, 2005. 
CROFT, W.. Radical construction grammar: syntactic theory in typological perspective. Oxford: Oxford University Press, 2001.

DANCYGIER, B.. Conditionals and prediction. Time, knowledge and causation in conditional constructions. Cambridge: Cambridge University Press, Cambridge Studies in Linguistics, v. 87, 1998. 214p.

ELY, L.. As construções condicionais em cartas pessoais do português brasileiro: uma análise baseada no uso. 2019. Dissertação (Mestrado em Linguística). Programa de Pósgraduação em Linguística, Universidade Federal da Fronteira Sul - Chapecó (SC).2019. Disponível em: https://rd.uffs.edu.br/bitstream/prefix/3249/1/ELY.pdf. Acesso em: 01 març. 2020.

FERNANDES, M. P. K. S.. A formação das microconstruções 'uma vez que', 'já que' e 'assim que': uma abordagem cognitivo-funcional. Tese (Doutorado em Linguística). Programa de Pós-Graduação em Linguística. Universidade Federal do Rio de Janeiro. Rio de Janeiro, 2019. Disponível em: http://www.ppglinguistica.letras.ufrj.br/images/Linguistica/3Doutorado/teses/2019/tese-biblioteca\%20-\%20pronto.pdf. Acesso em: 07 out. 2019.

FERRARI, L. V.. Construções gramaticais e a gramática das construções condicionais. Scripta, Belo Horizonte, v. 5, n. 9, p. 143-150, 20 sem. 2001. Disponível em: http:// periodicos.pucminas.br/index.php/scripta/article/view/11732. Acesso em: 10 nov. 2019.

FREITAG, R. M. K.. A expressão do passado iminencial em português: formas e contextos de uso. Anais do VII Congresso Internacional da Abralin, Curitiba - Paraná, 2011. Disponível em: https://www.sigaa.ufs.br/sigaa/ verProducao?idProducao=52732\&key=a3f283c99424340529. Acesso em: 01 dez. 2019.

FREITAG, R. M. K.; ARAUJO, A. S.. Passado condicional no português: formas e contextos de uso. Caligrama, Belo Horizonte, v.16, n.2, p.199-228. 2011. Disponível em: http://www.periodicos.letras.ufmg.br/index.php/caligrama/article/view/1624/1827. Acesso em: 04 abril 2020

FREITAG, R. M. K.; ARAUJO, A. S; BARRETO, E. A.. Emergência e regularização de usos em categorias verbais do português: gradações de modalidade nos valores condicional, iminencial e habitual no domínio do passado imperfectivo. Revista do Gelne, Natal/RN, vol. 15, número especial: 103-126. 2013.

FREITAG, R. M. K. et. al. As categorias verbais tempo, aspecto, modalidade e referência: pressupostos teóricos para uma análise semântico-discursiva. Estudos Lingüísticos, XXXV, p. 1463-1472, 2006. [1463 / 1472].

FURTADO DA CUNHA, M. A.. Funcionalismo. In: MARTELOTTA, M. E. (org.). Manual de linguística. 2. ed. 2012, p. 157-176.

FURTADO DA CUNHA, M. A.; BISPO, E. B.; SILVA, J. R.. Linguística funcional centrada no uso: conceitos básicos e categorias analíticas. In: CEZARIO, M. M.; FURTADO DA CUNHA, M. A. (Orgs.). Linguística centrada no uso: uma homenagem a Mário Martelotta. Rio de Janeiro: Mauad X: FAPERJ, 2013. 
GIVÓN, T.. Functionalism and grammar. Amsterdam/Philadelphia. Publishing Company, 1995.

GIVÓN, T.. Bio-linguistics: The Santa Barbara Lectures. Amsterdam/Philadelphia: Jonh Benjamins Publishing Company, 2002.

GRACIA, D. M.; SOUSA, G. C.. Construcionalização e mudança construcional de locuções conjuntivas em português: o caso de 'na hora que'. Revista Linguística, Rio de Janeiro, Vol.14, n1, p.232-250. 2018

GRYNER, H.. A variação de tempo-modo e conexão nas orações condicionais do português. 1990. p. 550. Tese (Doutorado em Linguística). Universidade Federal do Rio de Janeiro, Rio de Janeiro,1990. Disponível em: https://pantheon.ufrj.br/ bitstream/11422/6121/1/613532.pdf. Acesso em: 10 nov. 2019.

HIRATA-VALE, F. B. M.. A expressão da condicionalidade no português escrito do brasil: contínuo semântico-pragmático. 2005. p.149. Tese (Doutorado em Letras) Universidade Estadual Paulista, Faculdade de Ciências e Letras, Campus de Araraquara, 2005. Disponível em: https://repositorio.unesp.br/handle/11449/190768. Acesso em: 27 out. 2019.

HOPPER, P.; TRAUGOTT, E. C.. Grammaticalization. 2. ed. Cambridge: Cambridge University Press, 2003.

MARQUES, P. M.; PINTO, D. C. M.. Gramática como rede: relações entre construções. Revista LinguíStica / Revista do Programa de Pós-Graduação em Linguística da Universidade Federal do Rio de Janeiro. Volume Especial, dez de 2016, p. 128-138. ISSN 2238-975X 1. Disponível em: <http://www.letras.ufrj.br/poslinguistica/ revistalinguistica $>$ Acesso em: 10 març. 2020.

NEVES, M.H. M.. Gramática do portuguêsfalado. 2. ed. São Paulo: Humanistas/FFLCH/ USP; Campinas: Editora da Unicamp, 1999.

NEVES, M. H. M.. Gramática de usos do português. 2. ed. São Paulo. Editora: UNESP, 2011.

OLIVEIRA, T. P.. As conjunções e orações condicionais no português do Brasil. 2008. p. 155. Tese (Doutorado em Linguística) - Programa de Pós-Graduação em Linguística e Língua Portuguesa, Faculdade de Ciência e Letras, Unesp/Araraquara, São Paulo (SP), 2008. Disponível em: http://wwws.fclar.unesp.br/agenda-pos/linguistica_lingua_ portuguesa/1377. Acesso em: 21 nov. 2019.

OLIVEIRA, T. P.. A relevância do modelo em camadas para o estudo de estratégias comunicativas atualizadas pelas condicionais. In: PEZATTI, Erotilde G. (Org.). Pesquisas em gramática funcional: descrição do português. São Paulo: Ed. UNESP, 2009. p. 373383.

OLIVEIRA, T. P.. Conjunções adverbiais no português. Rev. Est. Ling., Belo Horizonte, v. 22, n. 1, p. 45-66, jan./jun. 2014. Disponível em: http://www.periodicos.letras.ufmg.br/ index.php/relin/article/view/5754. Acesso em: 01 nov. 2019. 
OLIVEIRA, T. P.; HIRATA-VALE, F.. A condicionalidade com zona conceitual. DELTA [online]. 2017, vol.33, n.1, pp.291-313. ISSN 0102-4450. Disponível em: http://www. scielo.br/scielo.php?script=sci_arttext\&pid=S0102-44502017000100291. Acesso em: 14 nov. 2019.

ROCHA LIMA. Gramática normativa da língua portuguesa / Rocha Lima. 49 ed. Rio de Janeiro: José Olympio, 2011 [1972].

ROSÁRIO, I. C.; OLIVEIRA, M.. Funcionalismo e Abordagem Construcional da Gramática. Alfa, São Paulo, v.60, n.2, p.233-259, 2016. Disponível em: http://www. scielo.br/pdf/alfa/v60n2/1981-5794-alfa-60-2-0233.pdf. Acesso em: 10 nov. 2019.

ROSÁRIO, I. C.; BARROS, L. M. M.. Construções proverbiais justapostas: parataxe ou hipotaxe?. Entrepalavras, Fortaleza, v. 8, n. 2, p. 361-380, maio/ ago. 2018.

ROST SNICHELOTTO, C. A.. Variação e Mudança no Português do Oeste de Santa Catarina, 2012. Plano de Trabalho Chamada Pública FAPESC n. 04/2012 Universal.

SILVA, T. S.. A formação de conectores concessivos e concessivo-condicionais instanciados pelo esquema [Xque] em português: uma análise construcional de mudança. Dissertação. Mestrado do Programa de Pós-graduação em Estudos Linguísticos. Universidade Federal do Rio de Janeiro. Rio de Janeiro. 2019. Disponível em: https://periodicos.ufrn.br/ odisseia/article/view/18065. Acesso em: 19 nov. 2019.

SOUSA, G. C.. Quando tempo é condição. In: PEZATTI, Erotilde G. (Org.). Pesquisas em gramática funcional: descrição do português. São Paulo: Ed. UNESP, 2009. p. 357-372.

SWEETSER, E.. From etymology to pragmatics: metaphorical and cultural aspects of semantic structure. Cambridge: Cambridge University Press, 1990.

TAVARES. M. A.. Sociofuncionalismo: um duplo olhar sobre a variação e a mudança linguística. Interdisciplinar. Edição Especial ABRALIN/SE, Itabaiana/SE, Ano VIII, v.17, jan./jun. 2013. Disponível em: https://seer.ufs.br/index.php/interdisciplinar/article/ download/1312/1162. Acesso em: 09 nov. 2019.

TRAUGOTT, E.; TROUSDALE, G.. Constructionalization and Constructional Changes. Great Clarendon Street, Oxford, ox2 6dp, United Kingdom, 2013.

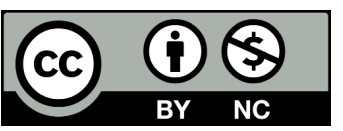

Data de submissão: 15/12/2019

Data de aceite: $26 / 03 / 2020$ 